\title{
PENGARUH VARIASI KADAR FILLER ABU CANGKANG KERANG TERHADAP PARAMETER MARSHALL DI LAPISAN LASTON AC-WC
}

\author{
Nunung Widyaningsih', Fiko Farnolo Hamzah² \\ 1,2Jurusan Teknik Sipil Universitas Mercu Buana \\ e-mail : fikohamzah@gmail.com
}

\begin{abstract}
In effort to increase the strength of pavement highways structure especially Laston pavement, choices of material as a filler is the material itself that needs to be subtle and can fill the cavity or pore, one of a waste that produced by palm oil industry provides alternative opportunities for composing asphalt mixture of constituent materials (filler). Test were done by two stages which is, testing the test object with portland cement filler so that the Marshall parameter and KAO value are achieved, and testing the test object with shellfish ash in order to get Marshall parameter and filler optimum content value. Test that were done at AC-WC layer mix was obtained KAO value in amount of $6,2 \%$ and filler optimum content value by $5,2 \%$. Stability value with $7 \%$ shellfish ash filler was obtained at 4810,787 kg by immersing the specimen for 30 minutes and $4203.7 \mathrm{~kg}$ with $7 \%$ shellfish ash filler with soaking specimens for 24 hours at $60{ }^{\circ} \mathrm{C}$.
\end{abstract}

Keyword : AC-WC ; filler; shellfish ash; Marshall.

\begin{abstract}
ABSTRAK
Dalam upaya meningkatkan kekuatan struktur perkerasan jalan raya khususnya perkerasan Laston, pemilihan jenis material sebagai filler merupakan bahan pengisi yang sifatnya halus dan dapat mengisi rongga atau pori, salah satu limbah yang dihasilkan oleh sampah cangkang kerang memberikan peluang alternatif material penyusun campuran aspal. Pengujian dilakukan dalam 2 tahap yaitu, pengujian benda uji dengan filler semen portland yang dilakukan untuk mendapatkan parameter Marshall dan nilai KAO dan pengujian benda uji dengan filler abu cangkang kerang untuk menghasilkan parameter Marshall dan nilai kadar filler optimum. Pengujian yang dilakukan pada campuran lapis AC-WC didapat nilai KAO sebesar $6,2 \%$ dan nilai kadar filler optimum $5,2 \%$. Nilai stabilitas dengan $7 \%$ filler abu cangkang kerang didapat $4810.787 \mathrm{~kg}$ dengan perendaman benda uji selama 30 menit dan $4203.7 \mathrm{~kg}$ dengan $7 \%$ filler abu cangkang kerang dengan perendaman benda uji selama 24 jam pada suhu $60^{\circ} \mathrm{C}$.
\end{abstract}

Kata Kunci : abu cangkang kerang; AC-WC; filler; Marshall.

\section{PENDAHULUAN}

Jalan raya sebagai prasarana sistem transportasi yang rutin digunakan dalam menopang aktifitas manusia setiap harinya harus memiliki kualitas yang memadai. Peningkatan jumlah kendaraan umum maupun pribadi mengakibatkan pada penggunaan jalan raya yang terus meningkat yang sebanding lurus dengan potensi kerusakan-kerusakan jalan raya tersebut jika tidak memiliki kualitas yang memadai. Salah satu faktor kualitas prasarana jalan raya adalah perkerasan jalan raya tersebut.

Aspal Beton (laston) merupakan campuran agregat kasar, agregat halus dan bahan pengisi (filler) dengan bahan pengikat aspal dalam kondisi suhu tinggi dengan komposisi yang diteliti dan diatur oleh spesifikasi teknis.

Melihat berbagai permasalahan yang ada, maka peneliti mencoba untuk menguji pengaruh filler terhadap campuran beraspal pada lapisan AC-WC (Asphalt Concrete-Wearing Concrete) dengan menggunakan abu cangkang kerang. 


\section{METODOLOGI}

Diagram alir (flow chart) dari penelitian ini dapat dilihat pada gambar 1.

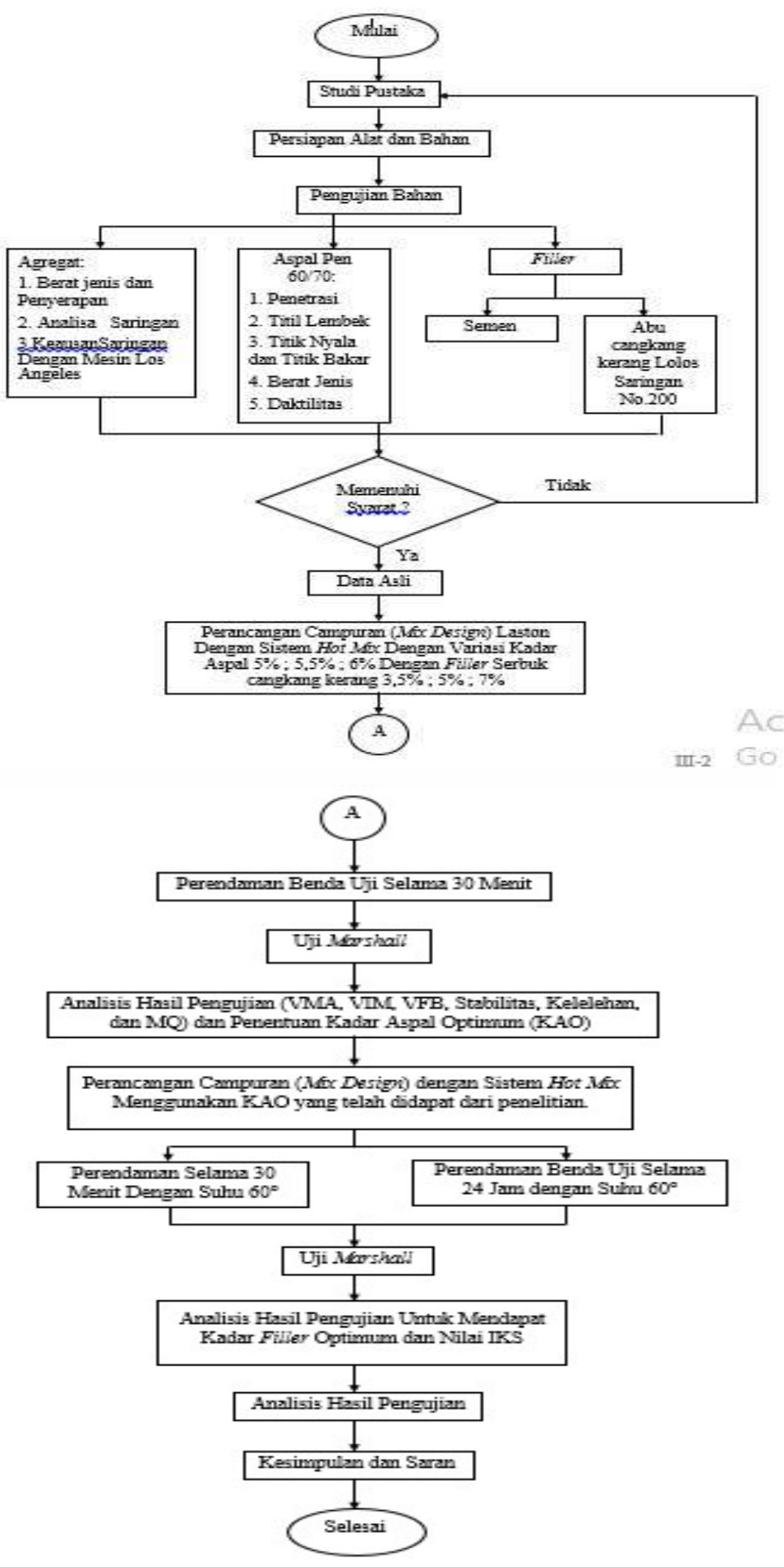

Gambar 1. Diagram Alir Penelitian

Sumber : Penelitian, 2019

\section{Metode Pencampuran Aspal}

Metode pencampuran aspal dapat dibedakan menjadi 3 kategori yakni pencampuran panas (HMA), pencampuran hangat (WMA), dan pencampuran dingin (CMA). Metode yang 
paling umum digunakan saat ini adalah pencampuran panas, karena karakteristik akhir campuran yang memenuhi persyaratan perkerasan.

Hot Mix Asphalt (HMA).

Aspal Hot mix merupakan campuran agregat kasar (batu screening/batu split), agregat halus (abu batu), filler, dengan mengunakan bahan pengikat aspal dalam kondisi suhu panas tinggi dengan komposisi yang teliti dan diatur oleh spesifikasi teknis. HMA diproduksi pada suhu $140^{\circ} \mathrm{C}-160^{\circ} \mathrm{C}$.

\section{Metode Uji Marshall}

Konsep dasar metode Marshall dalam campuran beraspal ditemukan oleh Bruce Marshall. Prinsip dasar dari metode Marshall adalah pemeriksaan stabilitas dan kelelehan, serta analisis kepadatan dan pori dari campuran padat yang terbentuk. Stabilitas adalah kemampuan suatu campuran beraspal untuk menerima beban sampai terjadi kelelehan plastis yang dinyatakan dalam satuan kilogram ataupun poun. Kelelehan plastis adalah keadaan perubahan bentuk campuran beraspal yang terjadi akibat suatu beban sampai batas runtuh yang dinyatakan dalam satuan millimeter ataupun 0.0001 inci.

Dari pengujian Marshall diperoleh data-data berikut :

- Kadar aspal, dinyatakan dengan bilangan desimal satu angka dibelakang koma.

- Berat volume, dinyatakan dengan satuan ton/m3.

- Stabilitas, dinyatakan dengan bilangan bulat.

- Kelelehan plastis (flow), dinyatakan dalam mm atau 0.01 inci.

- VIM, persen rongga dalam campuran dinyatakan dengan bilangan decimal satu angka di belakang koma. - VMA, persen rongga dalam agregat dinyatakan dengan bilangan bulat.

- Penyerapan aspal, persen terhadap berat campuran sehingga diperoleh gambaran berapa kadar aspal efektifnya.

- Tebal lapisan aspal, dinyatakan dengan satuan mm.

- Kadar aspal optimum, dinyatakan dengan bilangan desimal.

\section{Indeks Kekuatan Sisa (Indeks Of Retained Strength)}

Konsep dasar Indeks Kekuatan Sisa (IKS) ini yaitu perendaman pada waterbath pada temperature $60^{\circ} \mathrm{C}$ selama 30 menit (stabilitas standar) dan perendaman pada waterbath pada temperature $60^{\circ} \mathrm{C}$ selama 24 jam (stabilitas rendaman) yang berfungsi untuk mengetahui daya tahan terhadap pengrusakan oleh air.

\section{HASIL DAN PEMBAHASAN}

Ada beberapa hasil analisis yang diperoleh dari penelitian yang sudah dilakukan. Hasil analisis tersebut meliputi analisis perhitungan berat jenis agregat kasar, semen, abu cangkang kerang, Marshall test dengan filler abu cangkang dan portland cement, KAO dengan filler abu cangkang, KAO dengan portland cement serta Indeks Kekuatan Sisa (IKS). Hasil analisis tersebut diuraikan sebagai berikut :

1. Analisis Perhitungan Berat Jenis Agregat Kasar

Hasil analisis agregat kasar dengan berbagai parameter yang sudah ditentukan, dianalisis berdasarkan rumus yang ada. Hasil analisis dari perhitungan berat jenis agregat kasar ditunjukkan pada tabel1.

Tabel 1. Analisis Dan Hasil Tabel 10 Hasil Perhitugan Berat Jenis Agregat Kasar

\begin{tabular}{|c|c|c|c|c|}
\hline No & Parameter & Rumus & Hasil & Satuan \\
\hline 1 & $\begin{array}{c}\text { Berat BJ Kering Permukaan } \\
\text { Jenuh dalam Air }\end{array}$ & BA & 3075 & gram \\
\hline 2 & $\begin{array}{c}\text { Berat BJ Kering Permukaan } \\
\text { Jenuh }\end{array}$ & BJ & 5072 & gram \\
\hline
\end{tabular}




\begin{tabular}{|c|c|c|c|c|}
\hline 3 & Berat BJ Kering Oven & BK & 5000 & gram \\
\hline 4 & $\begin{array}{c}\text { BJ Kering (Bulk Specific } \\
\text { Grafity) }\end{array}$ & $\frac{B k}{B j-B a}$ & 2.503 & gram \\
\hline 5 & Saturated Surface Dry & $\frac{B j}{B j-B a}$ & 2.54 & gram \\
\hline 6 & Bj Semu & $\begin{array}{c}B k \\
B k-B a\end{array}$ & gram \\
\hline 7 & Penyerapan & $\begin{array}{c}\text { Bj-Bk } \\
x 100 \%\end{array}$ & 1.44 & $\%$ \\
\hline
\end{tabular}

Sumber : Hasil Penelitian, 2019

Dari tabel 10 hasil pengujian berat jenis agregat kasar didapat berat jenis 2,597 gram dan penyerapan 1,44 \%, ini sudah memenuhi syarat dalam SNI 03-1969-1990 dengan syarat berat jenis $>2,5$ dan penyerapan $<3 \%$.

2. Analisis Berat Jenis Berat Jenis Semen

Analisis dari hasil pengujian berat jenis semen dengan perhitungan yang ada dapat dilihat pada tabel 2 . Jenis semen yang dipilih adalah portland.

Tabel 2. Hasil Perhitungan Pengujian Berat Jenis Semen

\begin{tabular}{|c|c|c|c|c|}
\hline No & Keterangan & Rumus & $\begin{array}{c}\text { Hasil } \\
\text { Pengujian }\end{array}$ & Satuan \\
\hline 1 & Berat Filler & $\mathrm{Bt}$ & 64 & $\mathrm{gr}$ \\
\hline 2 & $\begin{array}{c}\text { Pembacaan Skala } \\
\text { Ke 1 }\end{array}$ & $\mathrm{V} 1$ & 0 & $\mathrm{cc}$ \\
\hline 3 & $\begin{array}{c}\text { Pembacaan Skala } \\
\text { Ke 2 }\end{array}$ & $\mathrm{V} 2$ & 21,8 & $\mathrm{cc}$ \\
\hline 4 & Berat Jenis & $\frac{B t}{V 2-V 1}$ & 2,936 & $\mathrm{gr} / \mathrm{cc}$ \\
\hline
\end{tabular}

Sumber : Hasil Penelitian, 2019

Dari tabel 2 ditunjukkan hasil pengujian bahwa berat jenis filler semen Portland di dapat nilai berat jenis 2,936 gr/cc. Hasil filler ini dapat memenuhi syarat SNI 15-2531-2008 denga syarat berat jenis $\geq 1 \mathrm{gr} / \mathrm{cc}$.

3. Analisis Pengujian Berat Jenis Abu Cangkang Kerang

Hasil analisis dari pengujian berat jenis abu cangkang kerang tertera pada tabel 3 .

Tabel 3. Pengujian Berat Jenis Abu Cangkang Kerang

\begin{tabular}{|c|c|c|c|c|}
\hline No & Keterangan & Rumus & $\begin{array}{c}\text { Hasil } \\
\text { Pengujian }\end{array}$ & Satuan \\
\hline 1 & Berat Filler & $\mathrm{Bt}$ & 64 & $\mathrm{gr}$ \\
\hline 2 & $\begin{array}{c}\text { Pembacaan Skala } \\
\text { Ke 1 }\end{array}$ & $\mathrm{V} 1$ & 0 & $\mathrm{cc}$ \\
\hline 3 & $\begin{array}{c}\text { Pembacaan Skala } \\
\text { Ke 2 }\end{array}$ & $\mathrm{V} 2$ & 22.5 & $\mathrm{cc}$ \\
\hline 4 & Berat Jenis & $\frac{B t}{V 2-V 1}$ & 2.844 & $\mathrm{gr} / \mathrm{cc}$ \\
\hline
\end{tabular}

Sumber : Hasil Penelitian, 2019 
4. Pengujian Marshall

Pada penelitian ini digunakan kadar aspal sebesar 5,5\%,6\%, dan 6,5\%. Dari pengujian Marshall didapat nilai presentase rongga dalam campuran (VIM), presentase rongga terisi aspal (VMA), presentase rongga terhadap agregat (VFA), stabilitas, kelelehan (flow) dan Marshall Quotient (MQ). Dan dari nilai tersebut maka akan didapat nilai Kadar Aspal Optimum (KAO). Hasil pengujian Marshal ditunjukkan pada tabel 6,7 dan 8. Sedangkan hubungan antara KAO dengan filler semen portland dan abu cangkang tertera pada gambar 2 dan 3.

Tabel 6. Hasil Marshall dengan Filler Semen Portland

\begin{tabular}{|c|c|c|c|c|}
\hline \multirow{2}{*}{ Keterangan } & \multicolumn{3}{|c|}{ Kadar aspal } & \multirow{2}{*}{ Syarat } \\
\hline & $5.5 \%$ & $6.0 \%$ & $6.5 \%$ & \\
\hline VMA (\%) & 16.44 & 14.46 & 14.86 & Min 14 \\
\hline VIM (\%) & 7.980043 & 4.337654 & 4.832812 & $3,5-5,5$ \\
\hline VFA (\%) & 53.2005 & 66.7915 & 70.2564 & Min 65 \\
\hline Stabilitas $(\mathrm{Kg})$ & 5833.284 & 5964.768 & 5220.538 & Min 800 \\
\hline $\begin{array}{l}\text { Kelelehan } \\
\quad(\mathrm{mm})\end{array}$ & 4.100 & 3.100 & 3.633 & Min 3 \\
\hline $\begin{array}{c}\mathrm{MQ} \\
(\mathrm{kg} / \mathrm{mm})\end{array}$ & 1421 & 1943 & 1456 & Min 250 \\
\hline
\end{tabular}

Sumber : Hasil Penelitian, 2019

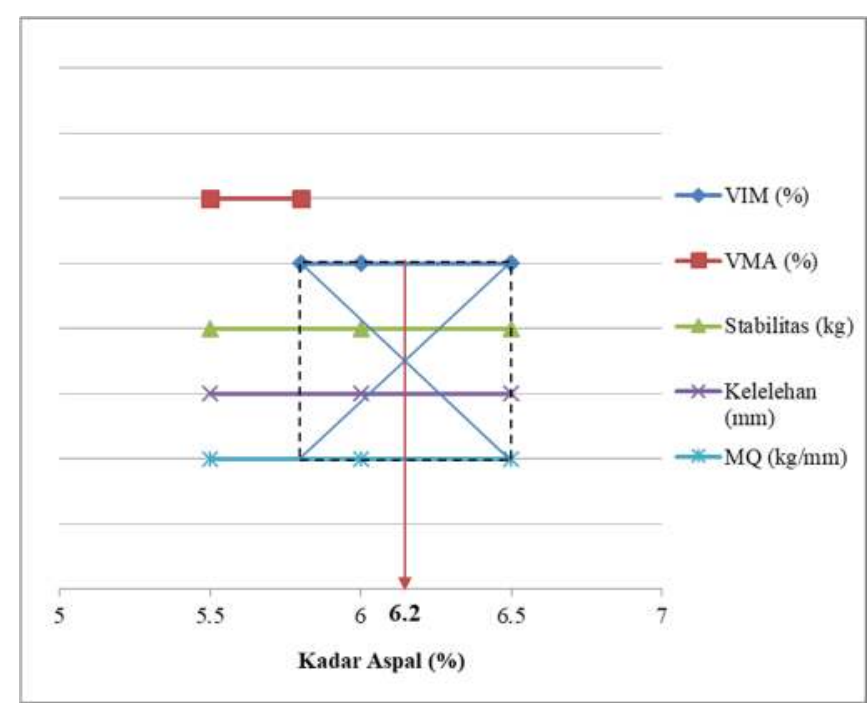

Gambar 2. Grafik KAO Dengan Filler Semen Portland

Sumber : Hasil Penelitian, 2019

Dari tabel 6 dan gambar 2, dapat dilihat bahwa kadar aspal dengan filler Semen Portland adalah memenuhi syarat.

Tabel 7. Hasil Marshall dengan Filler Abu Cangkang Kerang Pada IKS 30 Menit

\begin{tabular}{|c|c|c|c|c|}
\hline \multirow{2}{*}{ Keterangan } & \multicolumn{3}{|c|}{ Kadar Filler Abu Cangkang Kerang } & \multirow{2}{*}{ Syarat } \\
\cline { 2 - 4 } & $3.5 \%$ & $5.0 \%$ & $7.0 \%$ & Min 15 \\
\hline VMA (\%) & 14.021 & 14.165 & 14.096 & $3.5-5,5$ \\
\hline VIM (\%) & 4.23544 & 4.51332 & 4.42786 & Min 65 \\
\hline VFA (\%) & 71.699 & 70.620 & 71.075 & Min 800 \\
\hline $\begin{array}{c}\text { Stabilitas } \\
(\mathrm{kg})\end{array}$ & 4690.107 & 4894.679 & 4810.787 & Min 3 \\
\hline $\begin{array}{c}\text { Kelelehan } \\
(\mathrm{mm})\end{array}$ & 4.100 & 3.100 & 3.633 & \\
\hline
\end{tabular}




\begin{tabular}{|c|c|c|c|c|}
\hline $\begin{array}{c}\text { MQ } \\
(\mathrm{Kg} / \mathrm{mm})\end{array}$ & 1421 & 1943 & 1456 & Min 250 \\
\hline
\end{tabular}

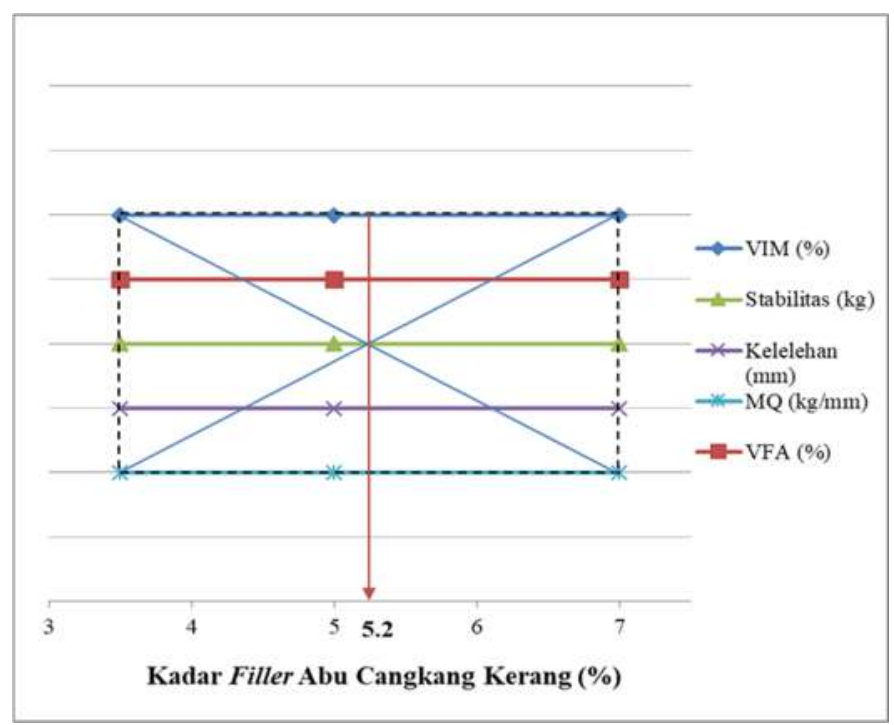

Gambar 3. Grafik Kadar Filler Optimum Abu Cangkang Kerang(IKS 30 menit) Sumber : Hasil Penelitian, 2019

Dari tabel 7 dan gambar 3, dapat dilihat bahwa kadar filler optimum abu cangkang dengan IKS 30 menit memenuhi batas minimal yang disyaratkan, yaitu di atas $250 \mathrm{~kg} / \mathrm{mm}$.

Tabel 8. Hasil Marshall dengan Filler Abu Cangkang Kerang Pada IKS 24 jam

\begin{tabular}{|c|c|c|c|c|}
\hline \multirow{2}{*}{ Keterangan } & \multicolumn{3}{|c|}{ Kadar Filler Abu Cangkang Kerang } & \multirow{2}{*}{ syarat } \\
\hline & $3.5 \%$ & $5.0 \%$ & $7.0 \%$ & \\
\hline VMA (\%) & 13.597 & 12.991 & 13.460 & Min 15 \\
\hline VIM (\%) & 3.762 & 3.570 & 3.719 & $3,5-5,5$ \\
\hline VFA (\%) & 73.995 & 78.172 & 74.852 & Min 65 \\
\hline Stabilitas $(\mathrm{Kg})$ & 4507.3 & 4732.2 & 4203.7 & Min 800 \\
\hline $\begin{array}{c}\text { Kelelehan } \\
(\mathrm{mm})\end{array}$ & 5.27 & 4.47 & 4.88 & Min 3 \\
\hline $\begin{array}{c}\mathrm{MQ} \\
(\mathrm{Kg} / \mathrm{mm})\end{array}$ & 857.38 & 1208.77 & 863.14 & Min 250 \\
\hline
\end{tabular}

Sumber : Hasil Penelitian, 2019

Dari tabel 8 ditunjukkan bahwa kadar filler optimum abu cangkang kerang dengan IKS 24 jam memenuhi batas minimal yang disyaratkan, yaitu di atas $250 \mathrm{~kg} / \mathrm{mm}$.

5. Perhitungan Indeks Kekuatan Sisa (IKS)

Pengujian ini berfungsi untuk mengetahui ketahanan (durability) perkerasan akibat pengaruh cuaca dan air. Tabel 9 menunjukkan nilai IKS.

Tabel 9. Indeks Kekuatan Sisa

\begin{tabular}{|c|c|c|c|c|}
\hline \multirow{2}{*}{$\begin{array}{c}\text { Kadar Abu Cangkang Kerang } \\
\text { (\%) }\end{array}$} & \multicolumn{2}{|c|}{ Nilai Stabilitas } & \multirow{2}{*}{ IKS (\%) } & \multirow{2}{*}{ Persyaratan } \\
\cline { 2 - 3 } & 30 menit & 24 jam & & \\
\hline 3,5 & 4690,107 & 4507,267 & 96,102 & \\
\hline 5 & 4894.679 & 4732.236 & 96,690 & \multirow{2}{*}{$>75 \%$} \\
\hline 7 & $4810 ., 787$ & 4203,747 & 87,382 & \\
\hline
\end{tabular}

Sumber : Hasil Penelitian, 2019

\section{KESIMPULAN}


Kesimpulan yang dapat diambil dari hasil penelitian yang dilakukan terhadap potensi penggunaan abu cangkang kerang sebagai filler terhadap campuran AC-WC menunjukkan bahwa nilai Kadar Aspal Optimum (KAO) yang didapat dari benda uji menggunakan filler semen portland pada campuran aspal AC-WC yaitu sebesar $6,2 \%$ dan penggunaan filler abu cangkang kerang dengan kadar $5 \%$ mengalami kenaikan pada nilai stabilitas. Nilai stabilitas dengan $7 \%$ filler semen Portland lebih tinggi dibandingkan dengan $7 \%$ filler abu cangkang kerang dalam perendaman selama 30 menit dan 24 jam dengan suhu $60^{\circ} \mathrm{C}$. Pada filler abu cangkang kerang, nilai stabilitas dengan perendaman benda uji selama 30 menit lebih tinggi dibandingkan perendaman selama 24 jam.

\section{DAFTAR PUSTAKA}

Advanty, E. 2016, Pengaruh Penggantian Sebagian Filler Semen dengan Kombinasi 40\% Serbuk Batu Bata dan 60\% Abu Cangkang Lokan pada Campuran Asphalt Concrete Binder Course (ac-bc), Program Studi Teknik Sipil, Fakultas Teknik, Universitas Bengkulu

Ahmad, B.N., Kartika, Indah, I.S, dan Yuyung, I.S., Ujung. 2014, Pengaruh Penggunaan Cangkang Kerang 15\% dan 25\% sebagai Pengganti Sebagian Agregat Kasar Terhadap Campuran Asphalt, Sekolah Tinggi Teknik Harapan, Medan.

Departemen Pekerjaan Umum.2007), Divisi 6 Perkerasan Aspal Spesifikasi Umum Bidang Jalan dan Jembatan.

Giovanni, D.J.,2017, Pengaruh Variasi Kadar Filler Serbuk Kulit Kerang Lokan Terhadap Parameter Marshall di Lapisan Laston ac-bc, Universitas Atma Jaya, Yogyakarta.

Elsa, A. 2018, The Influence of Palm Shell Shell Filler on AUS (AC-WC) Asphalt Concrete Mixture in Terms of the Marshall and Wheel Tracking Test Characteristics, Faculty of Engineering, Universitas Mercu Buana, Jakarta, 2018.

Fandy,A.,Alfian, M., dan Gunawan, W. 2018. Penggunaan Abu Kulit Kerang sebagai Bahan Pengisi (Filler) dalam Campuran Aspal Jenis ac-wc dengan Pengujian Marshall, Jurusan Teknik Sipil, Fakultas Teknik, Universitas Riau.

Nunung, W., Budi, S. 2017, Influence of Hyacinth Plant as Filler on Mixed ac-wc (Asphalt Concrete - Wearing Course) with Marshall Test', Faculty Of Engineering, Universitas Mercu Buana, Jakarta, 2017.

Nunung, W., Rifda, K.V. 2017, Effect of Glass Powder Filler and Husk Ash on Road Pavement with Marshall Test Using Warm Mix System in AC-WC Mixture, Faculty Of Engineering, Universitas Mercu Buana, Jakarta, 2017.

Rizki, C., Rika, S., dan Elma, Y. 2016, Perbandingan Nilai Stabilitas Penggunaan Filler Serbuk Kulit Kerang dengan Abu Batu pada Campuran Beton Aspal, Universitas Islam 45 Bekasi.

SNI 8198:2015. 2015, Spesifikasi Campuran Beraspal Panas Bergradasi Menerus (Laston), Badan Standarisasi Nasional, Jakarta. 
